\title{
An Electroanalytical Determination of Sunset Yellow in Food Product by Amplified Nanostructure Carbon Paste Electrode as Sensor
}

\author{
Zahra Mehdizadeh ${ }^{1}$, Seyed-Ahmad Shahidi ${ }^{1}$, Azade Ghorbani-HasanSaraei ${ }^{1, *}$, Mohammad Bagher \\ Limooei $^{2}$, Majedeh Bijad ${ }^{l}$ \\ ${ }^{1}$ Department of Food Science and Technology, Ayatollah Amoli Branch, Islamic Azad University, \\ Amol, Iran \\ ${ }^{2}$ Department of Materials Science and Engineering, Ayatollah Amoli Branch, Islamic Azad \\ University, Amol, Iran \\ *E-mail: azade380@yahoo.com, a.ghorbani@iauamol.ac.ir
}

doi: $10.20964 / 2021.04 .44$

Received: 4 December 2020 / Accepted: 1 February 2021 / Published: 28 February 2021

\begin{abstract}
A new and sensitive food analytical sensor was fabricated using the amplification of paste electrode (CPE) by CdO-SWCNTs and 1-methyl-3-butylimidazolium bromide (MBIZLB), which was then used to determine Sunset yellow (SY) in aqueous solution. The CPE/MBIZLB/CdO-SWCNTs showed excellent catalytic activity for oxidation of SY and improved its current activity up to about 6.12 times. FESEM image of CdO-SWCNTs nanocomposite displayed decoration of $\mathrm{CdO}$ nanoparticles at the surface of carbon nanotubes with a diameter about $30 \mathrm{~nm}$. On the other hand, square wave voltammograms of SY showed a linear dynamic range $0.0006-180 \mu \mathrm{M}$ with the detection limit of 0.3 $\mathrm{nM}$ using CPE/MBIZLB/CdO-SWCNTs as the working electrode. Finally, the CPE/MBIZLB/CdOSWCNTs was used for the determination of SY in juices samples by applying standard addition method with recovery range of 98.88 to $101.84 \%$.
\end{abstract}

Keyword: CdO-SWCNTs, Composite, sunset yellow, modified sensor

\section{$\underline{\text { FULL TEXT }}$}

(C) 2021 The Authors. Published by ESG (www.electrochemsci.org). This article is an open access article distributed under the terms and conditions of the Creative Commons Attribution license (http://creativecommons.org/licenses/by/4.0/). 